\title{
Hábitos de higiene genital y síndrome de flujo vaginal en una población de mujeres de Lima Metropolitana
}

\author{
Tito Valer, Luis Solano, Luis Rivas \\ Instituto de Patología, Facultad de Medicina, UNMSM
}

Objetivos: Determinar los hábitos de higiene en una población de mujeres con sindrome de flujo vaginal.

Diseño: Estudio descriptivo, observacional, transversal.

Institución: Instituto de Patología, Facultad de Medicina, UNMSM.

Participantes: Mujeres con flujo vaginal.

Intervenciones: A 272 mujeres con presencia de flujo vaginal, se les aplico una encuesta dirigida y se les tomó una muestra del flujo vaginal, para su estudio. Los datos fueron introducidos en el programa SPSS v. 20.0.0 para Windows, se hizo la distribución de las frecuencias y porcentajes.

Principales medidas de resultados: Hábitos de higiene en mujeres con flujo vaginal.

Resultados: $95,6 \%$ realizaba su higiene genital diariamente, 37,5\% utilizaba jabones perfumados para la higiene genital, $25,7 \%$ usaba jabones para lavar ropa, $63,2 \%$ infusiones de hierbas naturales, 13,9\% vinagre, 8,1\% manifestó lavarse las manos después de usar el servicio higiénico, 11,4\% practicaba sexo vaginal y anal, 93,8\% realizaba su higiene en dirección de adelante hacia atrás, $32,4 \%$ se rasuraba los vellos púbicos con frecuencia, $21,3 \%$ tenía dos compañeros sexuales al año, $36,8 \%$ tuvo entre 5 y 6 compañeros sexuales durante toda su vida.

Conclusiones: Existieron factores de riesgo en los hábitos de higiene, vestido, conducta sexual y desconocimiento de cómo realizar una higiene vaginal óptima. La enseñanza de hábitos de higiene de las madres a las hijas fue insuficiente.

Palabras clave: Vaginitis, higiene femenina, hábitos.

\section{Atención materna durante la comida, en niños de seis a doce meses de edad, en el distrito de Cochamarca, Oyón, Lima}

Gandy Dolores, Doris Delgado

Universidad Nacional Mayor de San Marcos

Objetivos: Conocer cómo es la atención materna durante la comida, en niños desde los seis a doce meses de edad.

Diseño: Etnográfico y narrativo.

Institución: Universidad Nacional Mayor de San Marcos.

Participantes: Madres con sus respectivos hijos.

Intervenciones: En hogares de niños de 6 a 12 meses de edad, de ambos sexos, del distrito de Cochamarca, Oyón, Lima. Los datos emergentes fueron a partir de 6 entrevistas a profundidad y 12 con observación directa durante la comida, con guias validadas por jueces expertos.

Principales medidas de resultados: Atención a las señales de hambre y saciedad durante la comida.

Resultados: Las madres representaron la principal persona encargada de la alimentación. Mostraron una actitud desinteresada para con las prácticas de una alimentación responsiva, ya que las madres mostraron cierto interés y atención hacia su hijo(a) solo cuando el niño(a) no quería comer o cuando ya se estaba comenzando a aburrir, debido a que las madres estuvieron más preocupadas por los quehaceres del hogar.

Conclusiones: Las madres tuvieron poca atención a las señales de hambre o saciedad de su hijo(a), porque le dieron mayor prioridad a las labores de casa y otros miembros de la familia, demostrando poca paciencia y motivación para atender a su hijo(a).

Palabras clave: Atención, hambre, saciedad, alimentación, madre, niños. 